\title{
Magnetotelluric Investigation of the Geo-Tectonic Stability of Campo-Ma'an Area in South Cameroon
}

\author{
Njingti-Nfor ${ }^{1,2}$, Owona Angue Marie Louise Clotilde ${ }^{1,2}$, Kue Petou Rokis Malquaire ${ }^{1,3,4 *}$, \\ Bisso Dieudonné1, Piameu Kwagag Jöel1
}

${ }^{1}$ Postgraduate School of Sciences, Technologies \& Geosciences, University of Yaoundé I, Yaoundé, Cameroon

${ }^{2}$ Department of Physics, Advanced Teacher Training College, University of Yaoundé I, Yaoundé, Cameroon

${ }^{3}$ National Institute of Cartography, Yaoundé, Cameroon

${ }^{4}$ School of Geosciences, China University of Petroleum, Qingdao, China

Email: *rokis.petou@yahoo.fr

How to cite this paper: Njingti-Nfor, Clotilde, O.A.M.L., Malquaire K.P.R., Bisso, D. and Jöel, P.K. (2017) Magnetotelluric Investigation of the Geo-Tectonic Stability of Campo-Ma'an Area in South Cameroon. International Journal of Geosciences, 8, 1427-1441.

https://doi.org/10.4236/ijg.2017.812084

Received: October 31, 2017

Accepted: December 16, 2017

Published: December 19, 2017

Copyright () 2017 by authors and Scientific Research Publishing Inc. This work is licensed under the Creative Commons Attribution International License (CC BY 4.0).

http://creativecommons.org/licenses/by/4.0/

\begin{abstract}
The magnetotelluric prospection method has been widely used in Cameroon not only as a reconnaissance method for geophysical investigations but also to determine the nature of the subsurface and the structural settings of the various geological formations in the country that resulted from the global geo-tectonic movements. The present study is aimed at employing the magnetotelluric method to provide evidence on major tectonic dislocations which might have led to the presence of plutonic intrusions in the cratonic structure of the Ntem Complex as well as determining the nature of the contact between the sedimentary Campo Basin and the metamorphic cratonic Ntem Complex. The analyses and interpretations of iso-resistivity maps and geoelectric sections from magnetotelluric data has enabled us to show that tectonic forces at contact between the sedimentary Campo Basin and the metamorphic Ntem Complex were of three different categories: gravity gliding, magmatic upwelling and lateral compressions. The results of the action of these forces were the development of vertical and sub-vertical faulting systems at Craton-Sedimentary Basin contact and subsidence of overburden that appears to have also paved the way for the setting-up of the Ntem River bed and its flood plains. This river bed and its flood plains have been characterized as having a sedimentary deposit depth of $500 \mathrm{~m}$ and width of $20 \mathrm{~km}$. Meanwhile, the deep-seated contact faulting systems within the two identified formations have varied fault magnitudes with a maximum of $60 \mathrm{~km}$. The relatively high apparently resistivity values (up to $1.0 \mathrm{k} \Omega \cdot \mathrm{m}$ ) for the sedimentary and the very high values for the metamorphic formations (up to and above $10.0 \mathrm{k} \Omega \cdot \mathrm{m}$ ) suggest that the
\end{abstract}


whole area is at present relatively geo-tectonically stable.

\section{Keywords}

Magnetotelluric, Tectonics, Intrusions, Gravity-Gliding, Upwelling, Compression

\section{Introduction}

The magnetotelluric prospection method has been widely used in Cameroon not only as a reconnaissance method for geophysical investigations but also to determine the nature of the subsurface and the structural settings of the various geological formations in the country that resulted from the global geo-tectonic movements [1] [2] [3] [4]. This method which employs natural telluric currents that are injected into the subsurface at technically selected frequencies allows for the determination of the apparent resistivity of the various layers of earth through which the electromagnetic waves pass. With the aid of these values of resistivity and using the principle of skin-effect, the pseudo-depths of penetration as well as other details about the subsurface arrangement of rocks and rock materials can be determined. The present study is aimed at employing the magnetotelluric method to provide evidence on tectonic dislocations which might have led to the presence of plutonic intrusions in the cratonic structure of the Ntem Complex in Cameroon as reported by several authors amongst whom are: [5] [6] [7] [8]; as well as determining the nature of the contact between the sedimentary Campo Basin and the metamorphic cratonic Ntem Complex.

\section{Geological and Tectonic Settings}

The entire African continent underwent a major phase of basement re-activation in the Late Precambrian, which resulted in the structural differentiation of the continent into stable cratonic nuclei, surrounded by mobile belts [9] [10]. This event has controlled the subsequent tectonic history that has affected the whole continent with the most recent events being the East African rift that was initiated some $30 \mathrm{Ma}$ to $40 \mathrm{Ma}$ [11]. Studies of absolute plate motion show that at present, the African plate is almost stationary and this may be the reason why some of the most recent tectonic movements in the continent have been dominated by vertical and oscillatory motions which have led to either intrusions from the underlying substratum or subductions of near-surface materials into the architectural settings of subsurface formations [5] [6].

The Congo Craton being one of the cratonic nuclei is a large sub-circular mass of about $5.7 \times 10^{6} \mathrm{~km}^{2}$ in area and has an approximate diameter of $2.5 \times$ $10^{3} \mathrm{~km}$, which comprises Archaean crust, early to mid-Proterozoic fold belt and Proterozoic cover [8]. The northwestern margin of the Archaean Congo Craton which is found in the South of Cameroon is called the Ntem Complex [12] [13]. 
The Ntem Complex is divided into three main structural domains: to the north there is a major thrust that marks the contact with the Pan-African orogenic mobile belt called the Yaounde group, to the northwest end there are the Nyong and Ayina series and in the south-central area the Ntem series [14]. The Ntem series is dominated by massive and banded plutonic rocks of the charnockite suite and by intrusive tonalites, trondhjemites and granodiorites [15]. The entire Ntem Complex in particular and the Congo Craton in general are involved in two of the three orogenic cycles that are known in Cameroon:

- The Liberian cycle which dates from the Archaean era (about 2.5 Ma old) and is bounded by major thrusts that separate the Ntem series from the Nyong unit to the Northwest and the Pan-African Yaoundé Group to the North of the Ntem Complex [16]. This era began with the intrusion of magmatic rocks from which the greenstone belts were derived. Greenstone belt formation was followed by diapiric intrusion of the Tonalite-Throngemite-Granodiorite (TTG) between 2900 and $2800 \mathrm{Ma}$, during the major tectono-metamorphic phase [15]. The structures formed are essentially vertically dipping and the metamorphism dominated by granulite facies rocks that ended with an important migmatization event, resulting in the intrusion of anatectic potassic granitoids [7].

- The Eburnean or Trans-Amazonian cycle that dates from the Palaeoproterozoic period (2.5 - 1.8 Ma ago). This corresponds to the Nyong and Ayina series found to the north western border and to the east of the Ntem complex [17]. This Eburnean orogenic cycle is characterized by intrusion of doleritic dykes; which cycle ended with either a thermal or hydrothermal event at around $1800 \mathrm{Ma}$ [15].

The present study area is found at the southwestern edge of the Ntem Complex and cuts across the southern portion of the Nyong and Ayina series and the southwestern portion of the Ntem series. It lies between latitude $2^{\circ} 22^{\prime} \mathrm{N}$ and $2^{\circ} 26^{\prime} \mathrm{N}$ and longitude $9^{\circ} 57^{\prime} \mathrm{E}$ and $10^{\circ} 41^{\prime} \mathrm{E}$, stretching from Campo through Nyabessan to $\mathrm{Ma}$ 'an, having a minimum altitude of $39 \mathrm{~m}$ at Campo and maximum of $554 \mathrm{~m}$ at Ma'an (Figure 1).

\section{Material and Methods}

\subsection{Magnetotelluric Data}

The magnetotelluric data used in this work was acquired during a field study that took place in March 2015 using an ECA 540 AMT resistivity meter which has a frequency range from $4.1 \mathrm{~Hz}$ to $2300 \mathrm{~Hz}$ giving a total number of twelve frequencies. Field data is acquired at points called sounding stations which are chosen as a function of the orientation of the geological features of interest such as faults and contacts that might have prompted the prospecting. For each station a Global Positioning System is first used to determine the angular coordinates and the altitude. Then, using the resistivity meter, twelve series of measurements are made in two predetermined perpendicular directions for the 


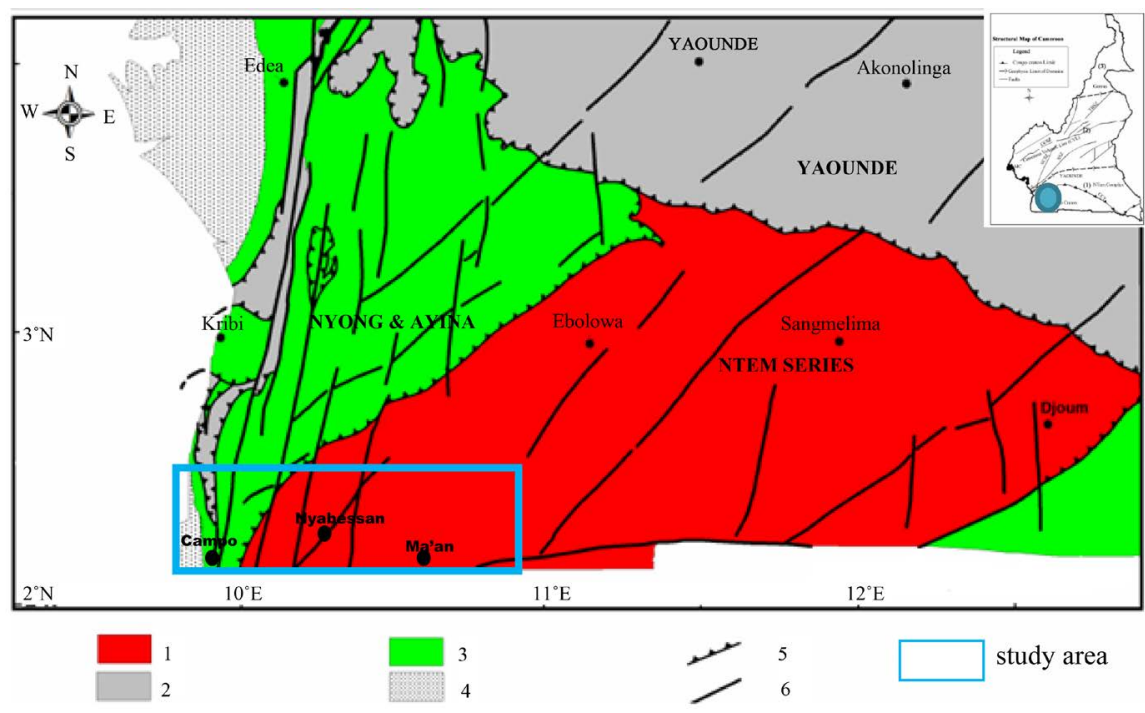

Figure 1. Simplified geological map of south Cameroon showing study area as modified from [18]. 1: Archaen basement; 2: Neoproterozoic cover; 3: Neoarchaen-Paleo-proterozoic cover; 4: Post Pan African cover; 5: Thrust fault; 6: fault.

component of electric field intensity, its mutually perpendicular component of magnetic field intensity and the values of the apparent resistivity. In the case of this data the principal directions were chosen in the North-South and East-West cardinal directions. For each frequency two average apparent resistivity values are got (one in each direction). The Audiomagnetotelluric data acquisition was conducted for 10 sounding stations, using the MT ECA 542-O resistivity meter [19], along the main highways from Campo to Ma'an. In the field, sounding stations were chosen as a function of the existing geographical features, the knowledge on the subsurface geology and accessibility. The area of study is found in a dense equatorial forest into which access was difficult except for open fields and roads and also because of the presence of the Campo-Ma'an national park that covers a great portion of the area and the Ntem river flood plains which are very swampy, woody and extremely inaccessible by foot. Some of the identified geological and geographical features are the contact between the sedimentary Campo Basin and metamorphic Ntem Complex, the Ntem River that flows in a NNE-SSW direction corresponding to the direction of major faults and the other streams that run in the area. The data for each sounding station is made of position (altitude, longitude and latitude), frequency of alternating telluric current, components of electric and magnetic fields and apparent resistivity of subsurface rocks. It is this data that have been used in the present study.

\subsection{Methodology}

\subsubsection{Apparent Resistivity Profiles}

Figure 2 shows a graphical representation of the sounding stations in terms of the angular coordinate system (longitudes and latitudes). Sounding stations 


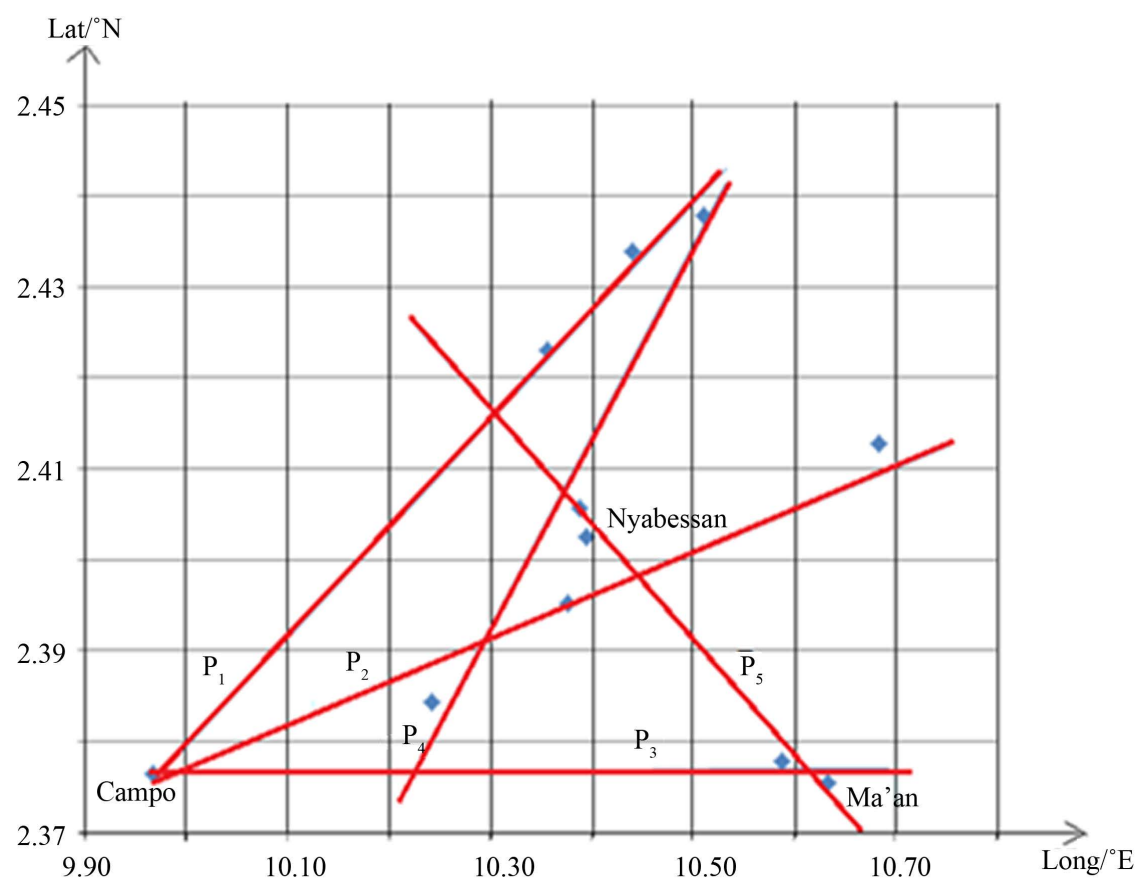

Figure 2. Graphical representation of the five profiles in the study area.

grouped and aligned in a chosen direction constitute a profile. There is a maximum of four sounding stations per profile for a total of five profiles $\left(\mathrm{P}_{1}\right.$ to $\left.\mathrm{P}_{5}\right)$. For each profile a particular sounding station has been chosen as base or control station with respect to which all other stations in the profile are referenced. Profiles 1, 2 and 3 have a common base station that is located in Campo at the edge of the Kribi-Campo sedimentary sub-basin. Profile 4 has a base station located at the exit of the Campo-Ma'an national park. These four profiles are oriented transverse to a suspected contact between the sedimentary Campo Basin and the metamorphic Ntem Complex. Profile 5 has its base station at Ma'an and is oriented transverse to the flow direction of the Ntem River which is in the NNE-SSW direction in this area.

\subsubsection{Geometric Mean Apparent Resistivity Values}

From the two values of apparent resistivity that are gotten in the two principal directions in the field a geometric mean value is calculated using the formula:

$$
\bar{\rho}=\sqrt{\rho_{a L} \rho_{a T}}
$$

where $\rho_{a L}$ and $\rho_{a T}$ represent the longitudinal and transverse apparent resistivity values respectively, which are both measured in $\Omega \cdot \mathrm{m}$.

The magnetotelluric method is based on the principle of the skin-effect [20]. According to this principle, the depth to which an electromagnetic wave penetrates into the earth subsurface depends on the frequency at which it impinges on the surface. When the frequency is very high the telluric current remains on a thin subsurface of the earth, called the pseudo-depth of penetration given by the Cagniard equation for magnetotelluric prospecting as: 


$$
P=0.503 \sqrt{\bar{\rho} T}
$$

where $\bar{\rho}$ is apparent resistivity measured in $\Omega \cdot \mathrm{m}$ and $T$ is period which the reciprocal of frequency measured in seconds $(s)$.

For each station and as a function of the frequency and geometric mean apparent resistivity value, the pseudo depth of penetration of the telluric current is determined

\subsubsection{Iso-Resistivity Contour Maps}

An iso-resistivity is a plot of the logarithm of the frequency of electromagnetic waves in descending order with increasing depth on the vertical axis against the distance from a base station taken as origin on the horizontal axis. This plot gives a series of contour lines that represent the paths connecting points with the same geometric mean apparent resistivity values. These contour lines provide a two-dimensional representation of the variation of apparent resistivity with depth for vertical cross-section through a slice of earth under consideration. They illustrate the shape of the structures within the sub-surface. According to [21], when the sub-surface is homogeneous and has uniformly varying apparent resistivity values, the contours are horizontal and parallel, uniformly spaced and unfolded. Abrupt changes in the values of apparent resistivity are indicated on the contour map by curved contour lines. These might be as results of folds, faults, fractures or intrusions. Contour lines that are in faulted areas have very high gradient with the contours closely packed together along the line of high gradient.

\subsubsection{Geoelectric Sections}

A geoelectric section is a two-dimensional presentation that is employed to show how the electrical properties (resistivity or conductivity) can be averaged over a large volume of earth, which may not necessarily be homogeneous [3]. For a layered sequence of rocks, the geoelectric section shows boundaries between layers represented by pronounced resistivity contrasts. The geolectric section is usually described as a function of parameters such as resistivity, conductance, resistance and coefficient of anisotropy. In the geoelectric section, it is possible to recognize structures like folds, faults and intrusions. A fault is recognized in a geoelectric section by a break in the continuity of the normal geoelectric sectional sequence [3]. Some amount of geoelectric section is always repeated or missing at the fault contact [22]. From the geolectric section, a measure of the fault magnitude is equal to the thickness of the missing or repeated section [23].

In this work, the geoelectric sections are all oriented in the same direction as the profiles and are derived from the iso-resistivity contour maps. On the geoelectric sections, resistivity values and pseudo-depths change downward into the subsurface. The pseudo-depths and lateral distances have been extended beyond the profile dimensions. An extension of the pseudo-depth enables us to determine the most probable origin of what might appear in the iso-resistivity contour map as an intrusion, a fault, a facture or a fold. An extension of the lateral 
distance beyond the length of the profile enables us to determine the extent of what might appear on the iso-resistivity contour map as a subsidence zone.

\section{Results and Interpretation}

\subsection{Analysis and Interpretation of ISO-Resistivity Contour Maps}

Figures 3(a)-3(e) give a presentation of iso-resistivity contour maps for the five profiles considered in this work. These maps have been obtained from the geometric mean apparent resistivity values using the MT2DInvMatlab computer program [24]. This is a two-dimensional modeling program for magneto-telluric data which works through a combination of two interactive algorithms in FORTRAN and MATLAB. MT2DInvMatlab employs the finite element method to calculate magneto-telluric 2-D responses with an incorporated smoothness-constraint least-square inversion method.

The colour codes in the Figures 3(a)-3(e) above vary from deep to light blue for resistivity values ranging from $0 \Omega \cdot \mathrm{m}$ to $1.0 \mathrm{k} \Omega \cdot \mathrm{m}$, from deep green to deep yellow for resistivity values ranging from $1.0 \mathrm{k} \Omega \cdot \mathrm{m}$ to $10.0 \mathrm{k} \Omega \cdot \mathrm{m}$ and finally from orange through red to deep purple for resistivity values ranging from 10.0 $\mathrm{k} \Omega \cdot \mathrm{m}$ to $5.0 \times 10^{4} \mathrm{k} \Omega \cdot \mathrm{m}$. The first range of resistivity values corresponds to rocks of sedimentary formation or weathered and unconsolidated metamorphic rocks [21]. The second range of resistivity values may correspond to sedimentary rocks or weathered metamorphic rocks that have been completely (re-)transformed into metamorphic rocks through the process of contact metamorphism. The third range of resistivity values may correspond to metamorphic rocks of plutonic origin which forms the Precambrian basement of the Ntem Complex.

The arrows in the Figures 3(a)-3(e), are of three categories: vertical or inclined arrows that point downwards indicate directions of subduction for near-surface materials, which might have been caused by the weight of the overburden; vertical or inclined arrows that point upwards indicate directions of uplift of underlying substratum materials and horizontal arrows that point sideward indicate lateral compression of materials [3]. The tectonic forces responsible for these materials movements are gravity gliding, magmatic and lateral compressive respectively.

The general nature of the contour lines in the Figures 3(a)-3(e), is such that they are either closed or open. The closed contour lines are around the $0.0 \Omega \cdot \mathrm{m}$ to $1.0 \mathrm{k} \Omega \cdot \mathrm{m}, 1.0 \mathrm{k} \Omega \cdot \mathrm{m}$ to $10.0 \mathrm{k} \Omega \cdot \mathrm{m}$ and the $10.0 \mathrm{k} \Omega \cdot \mathrm{m}$ to $5.0 \times 10^{4} \mathrm{k} \Omega \cdot \mathrm{m}$ resistivity values respectively. They are concentric contour lines that are either circular or ellipsoidal in shape. The closed contours around the $0.0 \Omega \cdot \mathrm{m}$ to $1.0 \mathrm{k} \Omega \cdot \mathrm{m}$, and $1.0 \mathrm{k} \Omega \cdot \mathrm{m}$ to $10.0 \mathrm{k} \Omega \cdot \mathrm{m}$ resistivity values represent material from the near surface of the earth that might have undergone subsidence due probably to either the weight of overburden from hydrostatic pressure or some lateral compressive forces and which became buried inside the architectural structure of relatively high resistivity materials. This is the case with Figures 3(b)-3(e). These closed contours around high resistivity values represent plutonic materials 


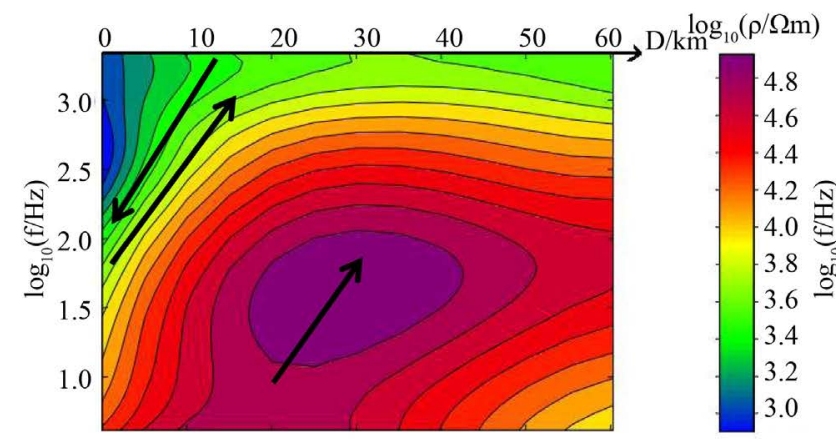

(a)

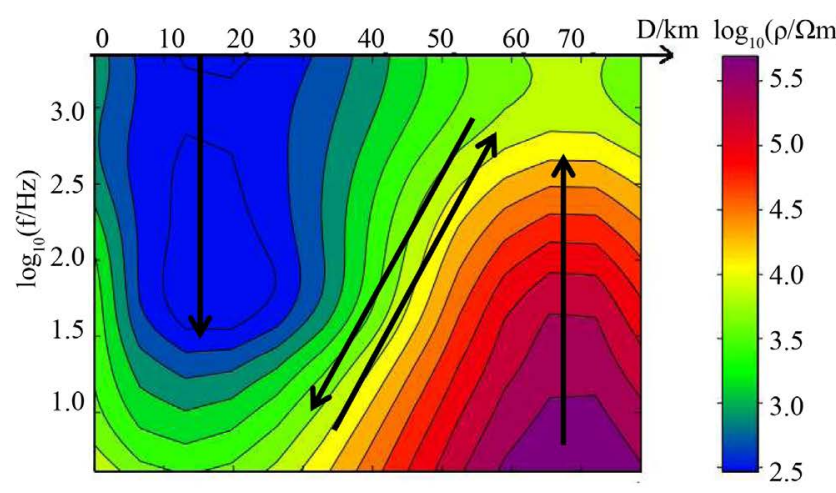

(c)

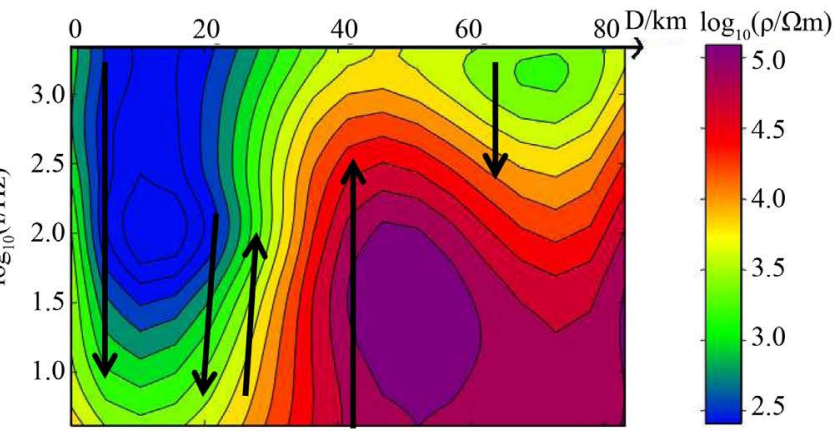

(b)

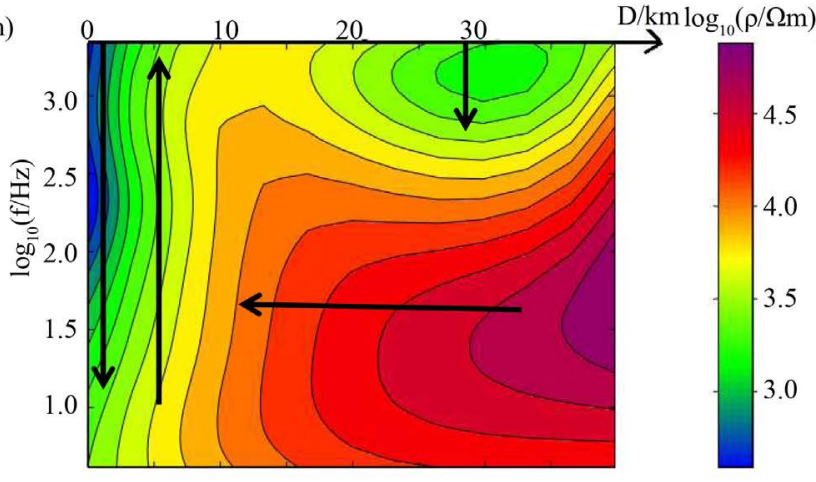

(d)

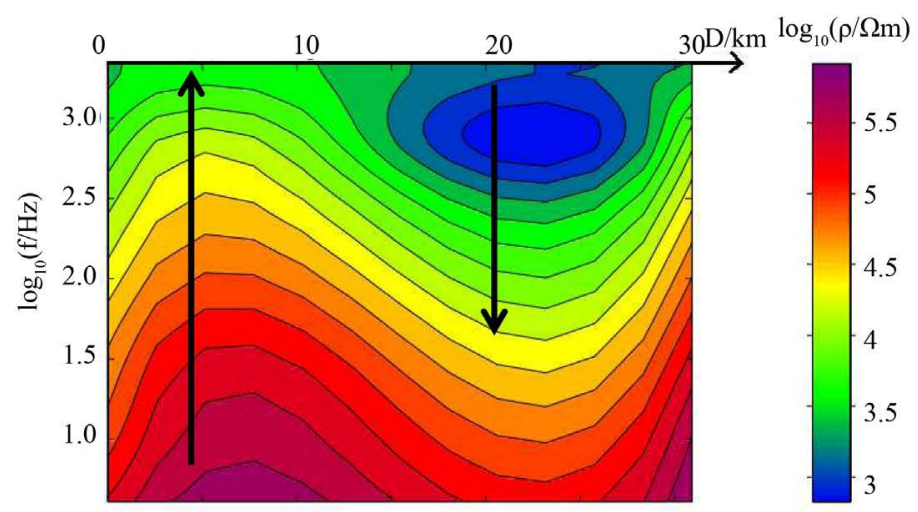

(e)

Figure 3. (a) Iso-resistivity contour map for profile 1 (Bearing $\mathrm{N} 84^{\circ} \mathrm{E}$ ); (b) Iso-resistivity contour map for profile 2 (Bearing $\left.\mathrm{N} 85^{\circ} \mathrm{E}\right)$; (c) Iso-resistivity contour map for profile $3\left(\mathrm{~N} 90^{\circ} \mathrm{E}\right)$; (d) Iso-resistivity contour map for profile 4 (Bearing N79 $\left.{ }^{\circ} \mathrm{E}\right)$; $(\mathrm{e})$ Iso-resistivity contour map for profile 5 (Bearing $97^{\circ} \mathrm{E}$ ). (The blue colour represents station while the red colour represents line-of-best fit through the chosen stations and direction).

of Precambrian origin (very high resistivity values) that welled up from underneath due probably to some upward vertical magmatic forces or laterally directed tectonic compressive forces and which became cut off from the substratum and lodged in the architectural structure of the relatively low resistivity materials. This intrusive material is found at a pseudo-depth range of between 12 $\mathrm{km}$ to $25 \mathrm{~km}$ for Figure 3 (a) and between $12 \mathrm{~km}$ to $71 \mathrm{~km}$ for Figure 3(b). For resistivity range of values from $0 \Omega \cdot \mathrm{m}$ to $1.0 \mathrm{k} \Omega \cdot \mathrm{m}$, the open contours that end upward shows that the same material that is exposed at the surface extends down 
into the subsurface to a pseudo-depth of about $3 \mathrm{~km}$ for Figure $3(\mathrm{~b})$, to a pseudo-depth of $5 \mathrm{~km}$ for Figure 3(c) and to a pseudo depth of $500 \mathrm{~m}$ only for Figure $3(\mathrm{e})$. Generally the rock materials of resistivity range of values from 1.0 $\mathrm{k} \Omega \cdot \mathrm{m}$ to $10.0 \mathrm{k} \Omega \cdot \mathrm{m}$ end up at some pseudo-depths before the complete attenuation of the telluric current. Although in some cases like in Figures 3(b)-3(d) where there is a probable contact between the sedimentary and the metamorphic formations, these averagely high resistivity materials are sandwiched between the two formations of very low and very high resistivity and also extend from the surface down to the basement. For these cases, it can be said that the zones of sandwich correspond to faults which are either vertical or sub-vertical in nature. Sub-vertical or completely vertical and parallel contour lines indicate violent tectonic forces that resulted to either fractures or faults. Generally such situations give rise to two formations of very low and very high resistivity values emplaced adjacent to each other. The open contour lines that start from the bottom of the map show that the material welled up from the subsurface at some depth that the telluric current could not reach and might therefore represent the substratum rocks which is Precambrian in nature. This is the case with all the five profiles. Horizontal and parallel iso-resistivity contours indicate uniform deposition and layering of material under less intense tectonic movements in which the material became consolidated through contact metamorphism with substratum material. This can be seen on Figure 3(a) between $20 \mathrm{~km}$ and $50 \mathrm{~km}$. Wavy contour lines indicate that the tectonic forces were of oscillatory nature and less violent with high resistivity material rising from below to form a crest and low resistivity material sinking from above to form a trough. This is the case with Figure 3(c) and Figure 3(e). These wavy and folded contours have materials of low resistivity on the synclinal portion and high resistivity materials on the anticlinal portions.

Overall, from the values of the resistivity, the material occupying a larger portion of the area of study is consolidated and can be considered to be globally metamorphic with sedimentary materials appearing only around the base stations of Figures 3(a)-3(d) and at the end of Figure 3(e). The orientation of Figure $3(\mathrm{e})$ is such that it cut across the Ntem River and the low resistivity materials to its extreme end seems to be derived from weathered metamorphic rocks of the Ntem Complex that are washed down and deposited in the flood plains and bed of the River.

The highly compressed and deformed nature of the iso-resistivity contour lines is suggestive of the violent nature of the tectonic forces that must have been at the origin of the emplacement of the rocks in this region.

\subsection{Analysis and Interpretation of Geoelectric Sections}

Figures 4(a)-4(e) give a presentation of the geoelectric sections for the five profiles in this work with respect to three parameters: the lateral spread of the stations from the base station, the pseudo-depth of penetration of the electromagnetic waves and the geometric mean values of apparent resistivity. 


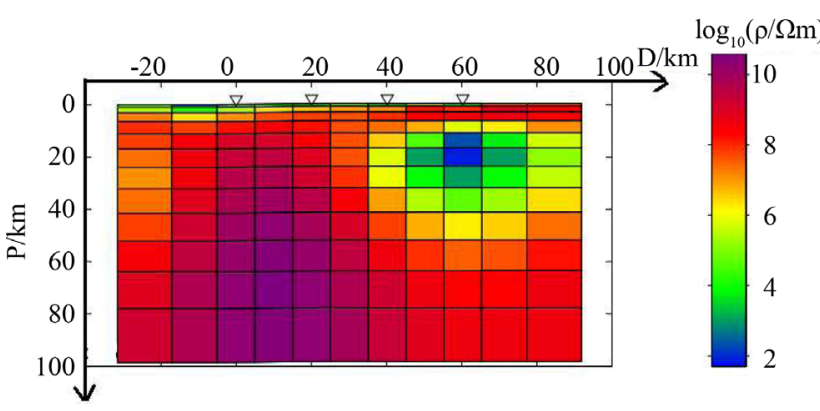

(a)

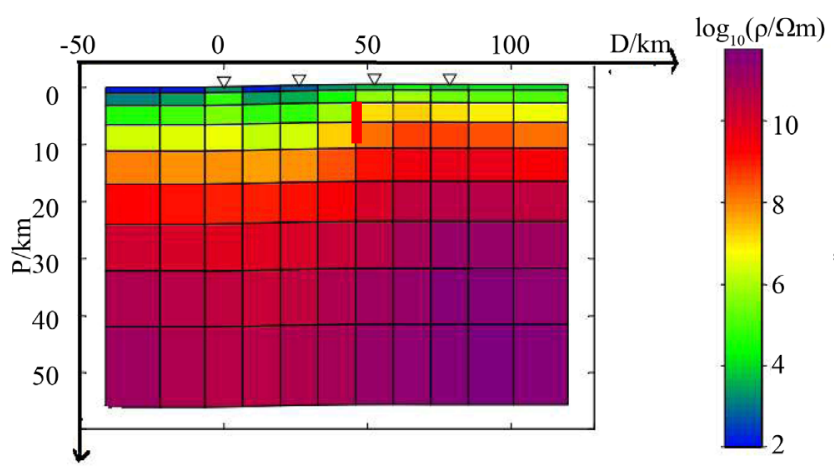

(c)

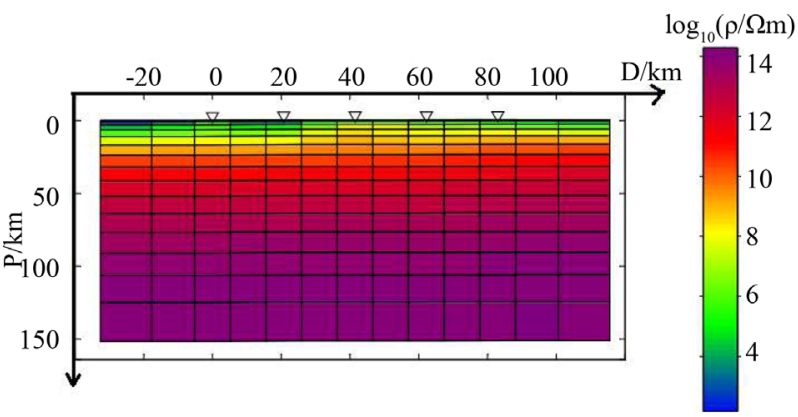

(b)

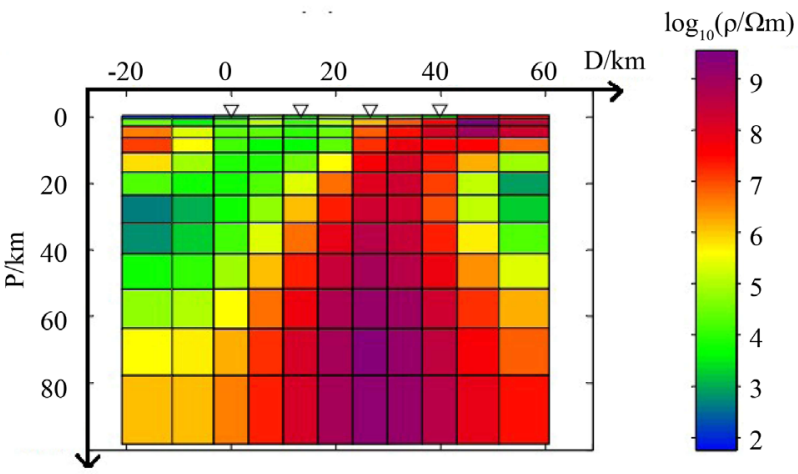

(d)

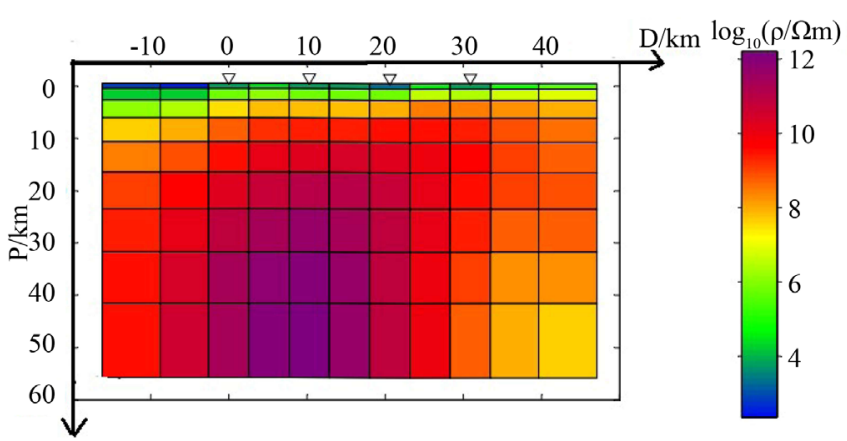

(e)

Figure 4. (a) Geoelectric section for profile 1; (b) Geoelectric section for profile 2; (c) Geoelectric section for profile 3 (: suspected fault); (d) Geoelectric section for profile 4; (e) Geoelectric section for profile 5. (The blue colour represents station while the red colour represents line-of-best fit through the chosen stations and direction).

A general observation of all the geoelectric sections reveals that: the low resistivity material $(0.0 \Omega \cdot \mathrm{m}$ to $1.0 \mathrm{k} \Omega \cdot \mathrm{m})$, blue colour code, is mostly found at near surface, hardly exceeding $1 \mathrm{~km}$ in depth, except in Figure 4(a) where this material is lodged inside the high resistivity material at an approximate pseudo-depth of $20 \mathrm{~km}$. At near surface, these low resistivity materials are mostly concentrated to the western extremes of the profiles, which are close to the contact zone between the sedimentary Campo basin and metamorphic Ntem Complex, and explains the sedimentary nature of the materials. On the other hand the low resistivity material found within the subsurface of Figure 4(a) seems to originate from a lateral embodiment of such material from a reverse faulting system to the far end of the geoelectric section, which might have been due to 
the effect of the intrusive body in Figure $3(\mathrm{a})$ above. The moderately high resistivity material $(1.0 \mathrm{k} \Omega \cdot \mathrm{m} \leq \rho \leq 10.0 \mathrm{k} \Omega \cdot \mathrm{m})$, from deep green to deep yellow colour is generally not uniformly distributed for the various geoelectric sections as this is often interrupted by very high resistivity material $(\rho>10.0 \mathrm{k} \Omega \cdot \mathrm{m})$ of colour from red to deep purple. The missing or repeated green to deep yellow colours represent either faulted structures or lineaments. Such is the case with geoelectric sections of Figures 4(a)-4(d).

With this premise, it can be seen that most of the subsidence zones (resistivity values ranging from $(0.0 \Omega \cdot \mathrm{m}$ to $1.0 \mathrm{k} \Omega \cdot \mathrm{m})$, revealed by the iso-resistivity map are superficial and do not go beyond the depth of $500 \mathrm{~m}$ in most cases. The lateral tectonic compressive forces identified in the iso-resistivity contour map were equally superficial and rock materials affected by these forces which fall within the resistivity values ranging from $1.0 \mathrm{k} \Omega \cdot \mathrm{m} \leq \rho \leq 10.0 \mathrm{k} \Omega \cdot \mathrm{m}$ are found mostly between depths of $0.0 \mathrm{~km} \leq P \leq 10.0 \mathrm{~km}$ as can be seen in geoelectric sections of Figures $4(\mathrm{a})-4$ (d). The magmatic forces that led to the very high resistivity $(\rho>10.0 \mathrm{k} \Omega \cdot \mathrm{m})$ intrusive body identified in iso-resistivity contour map of profiles 1 and 2 were deep-seated in nature and came from depths beyond $60 \mathrm{~km}$ as can be seen in the geoelectric section of Figure 4(b). The emplacement of the intrusive body due to contact between the sedimentary and metamorphic formations as revealed in the iso-resistivity contour maps of profiles 1,2 and 4 resulted to a fault whose magnitude is above $60 \mathrm{~km}$ deep as can be seen in the geoelectric section of Figure 4 (d). The geoelectric section representation has also put into evidence the existence of a low resistivity body $(0.0 \Omega \cdot \mathrm{m} \leq \rho \leq 10.0 \mathrm{k} \Omega \cdot \mathrm{m})$ lodged within the structures of the relatively high resistivity materials $(1.0 \mathrm{k} \Omega \cdot \mathrm{m}$ $\leq \rho \leq 10.0 \mathrm{k} \Omega \cdot \mathrm{m})$ as can be seen in the geolectric section of Figure 4(a). The body has a lateral length of about $20 \mathrm{~km}$ with high amplitude at $60 \mathrm{~km}$ from the base station and thickness at high amplitude of about $10 \mathrm{~km}$. The intrusive body that was identified in Figure 3(a) can be seen here to occupy a major portion of the geoelectric section and is bounded on both sides by faulted structures. In Figure $4(\mathrm{~b})$, the geoelctric section is generally occupied by the high resistivity materials ( $\rho>10.0 \mathrm{k} \Omega \cdot \mathrm{m}$ ), which starts from a pseudo-depth of about $25 \mathrm{~km}$ to beyond $150 \mathrm{~km}$. The averagely high resistivity materials $(1.0 \mathrm{k} \Omega \cdot \mathrm{m} \leq \rho \leq 10.0$ $\mathrm{k} \Omega \cdot \mathrm{m})$ is found at a depth range from $(P<1 \mathrm{~km}$ to $P=25 \mathrm{~km})$. In Figure $4(\mathrm{c})$, the low resistivity materials is found at shallow pseudo-depth of less than $500 \mathrm{~m}$ to the left of the geoelectric section and is completely missing to the right, where it is replaced by the averagely high resistivity materials which starts to the left at a pseudo-depth of $10 \mathrm{~km}$ to the right of the section at a pseudo-depth of about 5 $\mathrm{km}$. This is indicative of the existence of a fault of magnitude $5 \mathrm{~km}$ around the middle of the section at $50 \mathrm{~km}$ from the base station. The geoelectric section of Figure 4(d) shows that the upwelling of high resistivity materials $(\rho>10.0$ $\mathrm{k} \Omega \cdot \mathrm{m}$ ), to the near surface at $40 \mathrm{~km}$ from the origin created a step-faulting system with subsidence of low resistivity materials to the left to a depth of over 80 $\mathrm{km}$ and to the right to a depth of over $40 \mathrm{~km}$. Generally speaking the basement rock of this area of study of resistivity $(\rho>10.0 \mathrm{k} \Omega \cdot \mathrm{m})$, is believed to be of Pre- 
cambrian origin seems to be highly consolidated and stable.

\section{Discussion}

The results presented in the preceding sections confirm the reasons for the existence of certainty physical, geographical and geologic features in the study area and revealed the origin of the tectonic forces responsible for the putting in place of these features. These forces have been classified in three categories: gravity gliding from hydrostatic pressure forces due to the weight of the overburden leading to subsidence, upwelling magmatic forces leading to intrusions and lateral compressive forces leading to folds. In the cases where all the forces acted together the resultant effect was the development of faulted structures.

From Figures 3(a)-3(d), it has been shown that the transition between Kribi-Campo sedimentary sub-basin and the metamorphic Ntem Complex (northern part of the Congo Craton) was a tectonic collision at contact resulting from a combination of all the three aforementioned forces leading to the sub-vertical and vertical faulting systems separating the sedimentary low resistivity formation from the metamorphic high resistivity formation. This contact faulting systems are particularly marked by the subduction of low resistivity sedimentary material around Campo and the uplift of high resistivity metamorphic material leading to intrusive bodies between Campo and Nyabessan. The low resistivity values of rock materials around Campo are an indication of the fact that the sedimentary formation of the Kribi-Campo sedimentary sub-basin extends onshore from the Atlantic Ocean. The effects of the faulted structures are deep-seated going to a pseudo-depth of over $60 \mathrm{~km}$. This confirms the findings by [7] according to which structures formed in the Ntem Complex are essentially vertically dipping and their metamorphism dominated by granulite facies rocks that ended with an important migmatization event, resulting in the intrusion of anatectic potassic granitoids.

The orientation of profile 5 (Figure 3(e) and Figure 4(e)), which is NW-SE reveals the existence of a low resistivity subsidence zone between Ma'an and Nyabessan which stretches over a lateral distance of over $20 \mathrm{~km}$ and a pseudo-depth of about $500 \mathrm{~m}$. This subsidence zone corresponds to the flood plains of the Ntem River in this area. The wavy nature of the iso-resistivity contour map of this profile (Figure 3(e)) shows that the tectonic forces were oscillatory in nature creating a folding structure and probably paving the way for the setting up of the Ntem River bed and its flood plains. In this work it is shown that the Ntem River bed and its flood plains is made up of a deposition of low resistivity material of sedimentary origin. This probably might be part of the metamorphic formation that has been weathered and washed down stream by the water current over the years and deposited along the river channel and its flood plains. This material though of metamorphic origin is not completely consolidated and therefore is both permeable and porous thus less resistive. The flood plains of this river channel and its base are flanked by relatively high resistivity materials 
thus making it stable. This is depicted in Profile 5 by the blue colour depression between $10 \mathrm{~km}$ and $30 \mathrm{~km}$.

Our study shows that despite the intense nature of the tectonic movements that might have been at the origin of the various deep-seated faults, zones of subsidence and intrusions in the area of study, probably during the periods of continental collision and the opening of the South Atlantic Ocean the area is relatively tectonically stable.

\section{Conclusion}

This work was aimed at employing the magnetotelluric method to provide evidence on tectonic dislocations which might have led to the presence of plutonic intrusions in the cratonic structure of the Ntem Complex, as well as determining the nature of the contact between the sedimentary Campo Basin and the metamorphic cratonic Ntem Complex. With data collected for 10 sounding stations and organized in 5 profiles, iso-resistivity contour maps and geo-electric sections were drawn. Using the results, it has been shown that the tectonic forces responsible for the putting in place of the metamorphic and sedimentary formations in the area of study were of three different origins: gravity gliding, magmatic and lateral compressive. These forces were more pronounced at the contact between the Kribi-Campo sedimentary sub-basin and the metamorphic Ntem Complex resulting to vertical and sub-vertical faulting systems. Within the Ntem complex itself, the forces were responsible for the emplacement of the Ntem River bed and its flood plains. The relatively high values of the apparent resistivity for the sedimentary formation as well as the very high values for the metamorphic formation have led us to the conclusion that the zone is at present, relatively tectonically stable.

\section{Acknowledgements}

Our acknowledgements go to the Ministry of Higher Education and Scientific Research of Cameroon as well as the University of Yaounde I for assisting us with the resources to carry out this research, as well as to the authority of the Memve'ele Hydro Electricity Dam Project for giving us access to collect data around the Ntem River at Nyabessan.

\section{References}

[1] Manguelle-Dicoum, E., Bokosah, A.S. and KwendeMbanwi, T.E. (1992) Geophysical Evidence of a Major Precambrian Schist-Granite Boundary in Southern Cameroon. Tectonophysics, 205, 437-446. https://doi.org/10.1016/0040-1951(92)90447-E

[2] Mbom-Abane, S. (1997) Investigation géophysiques en bordure du Craton du Congo et implications structurales. Thèse de Doctorat ès Sciences, Université de Yaoundé, Yaoundé, $180 \mathrm{p}$.

[3] Njingti-Nfor (2004) New Methods of Analysing and Interpreting Audiomagnetotellurics Data. Doctorate thesis, University of Yaoundé I, Yaoundé, 185 p.

[4] OwonaAngue, M.L.C., Nguiya, S., Nouayou, R., TokamKamga, A.P. and Man- 
guelle-Dicoum, E. (2011) Geophysical Investigation of the Transition Zone between the Congo Craton and the Kribi-Campo Sedimentary Basin (South-West Cameroon). South African Journal of Geology, 114, 145-158.

[5] Burke, K. and Wilson, J.T. (1972) Is the African Plate Stationary? Nature, 239, 387-390. https://doi.org/10.1038/239387b0

[6] Hartley, R., Watts, A. and Fairhead, J. (1996) Isostasy of Africa. Earth and Planetary Science Letters, 137, 1-18. https://doi.org/10.1016/0012-821X(95)00185-F

[7] Tadjou, J.M., Nouayou, R., Kamguia, J., Kande, H.L. and Manguelle-Dicoum, E., (2009) Gravity Analysis of the Boundary between the Congo Craton and the Pan-African Belt of Cameroon. Australian Journal of Earth Sciences, 102, 71-79.

[8] Shang, C.K., Liégeois, J.P., Satirb, M., Frisch, W. and Nsifa, E.N. (2010) Late Archaean High-K Granite Geochronology of the Northern Metacratonic Margin of the Archaean Congo Craton, Southern Cameroon: Evidence for Pb-Loss Due to Non-Metamorphic Causes. Gondwana Research, 18, 337-355. https://doi.org/10.1016/j.gr.2010.02.008

[9] Kennedy, W.Q. (1964) The Structural Differentiation of Africa in the Pan-African ( \pm 500 m.y.) Tectonic Episode. Leeds University Research Institute of African Geology and Department of Earth Sciences Annual Report on Scientific Results, 8, 48-49.

[10] Kennedy, W. (1996) The Influence of Basement Structure on the Evolution of the Coastal (Mesozoic and Tertiary) Basins, in Salt Basins around Africa. In: Ion, D., Ed., the Institute of Petroleum, London, 7-16.

[11] Burke, K. (1996) The African Plate. South African Journal of Geology, 99, 339-410.

[12] Goodwin, A.M. (1991) Precambrian Geology-The Dynamic Evolution of the Continental Crust. Academic Press, Harcourt Brace Jovanovich Publishers, San Diego, CA, $666 \mathrm{p}$.

[13] Maurizot, P., Abessolo, A, Feybesse, J.L., Johan V. and Lecomte P. (1986). Etude et prospection minière du Sud-Ouest Cameroun. Synthèse des travaux de 1978 à 1985. Rapport BRGM, Orléans 85, CMR 066, 274 p.

[14] Nedelec, A., Nsifa, E.N. and Martin, H. (1990) Major and Trace Element Geochemistry of the Archaean Ntem Plutonic Complex (South Cameroon): Petrogenesis and Crustal Evolution. Precambrian Research, 47, 35-50. https://doi.org/10.1016/0301-9268(90)90029-P

[15] Tchameni, R., Mezger, K., Nsifa, N.E. and Pouclet, A. (2001) Crustal Origin of Early Proterozoic Syenites in the Congo Craton (Ntem Complex), South Cameroon. $\mathrm{Li}$ thos, 57, 23-42. https://doi.org/10.1016/S0024-4937(00)00072-4

[16] Takam, T., Mokoto, A., Kokonyangi, J., Dunkley, D.J. and Nsifa, E.N. (2009) Paleo-Archaeancharnockite in the Ntem Complex, Congo Craton, Camroon: Insights from SHRIMP Zircon U-Pb Ages. Journal of Mineralogical and Petrological Sciences, 104, 1-11.

[17] Noel, E.O.P., Marcelin, M.P. and Bekoa, A. (2014) Crustal Structure and Seismogenic Zone of Cameroon: Integrated Seismic, Geological and Geophysical Data. Open Journal of Earthquake Research, 3, 152-161. https://doi.org/10.4236/ojer.2014.34015

[18] Clotilde, O.A.M.L., Patrick, A.S., NjingtiNfor, N., Daniel, N.J., Theophile, N.M., Rokis, K.P. and Dieudonné, B. (2016) Determination of the Structural Lineaments in the Kribi-Campo-Ma'an Area from a Multi-Scale Analysis of Gravity Data using the HGM and Euler 3D Deconvolution Approaches. International Journal of Geos- 
ciences, 7, 1122-1143. https://doi.org/10.4236/ijg.2016.79085

[19] Benderitter, Y. (1982) Interprétation des mesures magnétotelluriques obtenues avec un résistivimètre ECA. CNRS, CRG, Garchy.

[20] Cagniard, L. (1953) Basic Theory of the Magnetotelluric Method of Geophysical Prospecting. Geophysics, 18, 605-635. https://doi.org/10.1190/1.1437915

[21] Manguelle-Diccoum, N.-N., Mbom-Abane, E. and Tadjou, J.M. (2001) Evidence of Major Tectonic Dislocations along the Southern Edge of the Pan African Mobile Belt and the Congo craton Contact in the Southern Region of Cameroon. The 2nd International Conference on the Geology of Africa, Vol. 1, Assuit, 799-811.

[22] Redmond, J.L. (1972) Null Combination in Fault Interpretation. Bulletin-American Association of Petroleum Geologists, 56, 150-166.

[23] Bates, R.L. and Jackson, J.A. (1987) Glossary of Geology. 3rd Edition, American Geological Institute, Alexandria, $788 \mathrm{p}$.

[24] Lee, S.K., Kim, H.G., Song, Y. and Lee, C. (2009) MT2DInvMATLAB_a Program in Fortran and MATLAB for 2D Inversion. Computer and Geoscience, 35, 1722-1734. 